\title{
Noctilucent clouds: modern ground-based photographic observations by a digital camera network
}

\author{
Audrius Dubietis, ${ }^{1, \star}$ Peter Dalin, ${ }^{2}$ Ričardas Balčiūnas, ${ }^{1}$ Kazimieras Černis, ${ }^{3}$ \\ Nikolay Pertsev, ${ }^{4}$ Vladimir Sukhodoev, ${ }^{4}$ Vladimir Perminov, ${ }^{4}$ Mark Zalcik, ${ }^{5}$ \\ Alexander Zadorozhny, ${ }^{6}$ Martin Connors, ${ }^{7}$ Ian Schofield, ${ }^{7}$ Tom McEwan, ${ }^{8}$ \\ lain McEachran, ${ }^{8}$ Soeren Frandsen, ${ }^{9}$ Ole Hansen, ${ }^{10}$ Holger Andersen, ${ }^{10}$ \\ Jesper Grønne, ${ }^{10}$ Dmitry Melnikov, ${ }^{11}$ Alexander Manevich, ${ }^{11}$ \\ and Vitaly Romejko ${ }^{12}$
}

'Department of Quantum Electronics, Vilnius University, Sauletekio Avenue 9, Building 3, LT-10222 Vilnius, Lithuania

${ }^{2}$ Swedish Institute of Space Physics, Box 812, SE-981 28 Kiruna, Sweden

${ }^{3}$ Institute of Theoretical Physics and Astronomy, Vilnius University, A. Goštauto 12, LT-01108 Vilnius, Lithuania

${ }^{4}$ A. M. Obukhov Institute of Atmospheric Physics, Russian Academy of Sciences, Pyzhevskiy pereulok, 3, Moscow 119017, Russia

${ }^{5}$ NLC CAN AM Network, \#7 1413080 Street, Edmonton, T5C 1L6 Alberta, Canada

${ }^{6}$ Novosibirsk State University, Pirogova Street 2, Novosibirsk 630090, Russia

${ }^{7}$ Athabasca University Geophysical Observatory, Athabasca, Alberta T9S 3A3, Canada

${ }^{8}$ NLC NET, 14 Kersland Road, Glengarnock, Ayrshire KA14 3BA, Scotland, UK

${ }^{9}$ University of Aarhus, Ny Munkegade, Building 1520, DK-8000 Aarhus C, Denmark

${ }^{10}$ The Danish Association for NLC Research, Lyngvej 36, Kolvrå, DK-7470 Karup J., Denmark

${ }^{11}$ Institute of Volcanology and Seismology, Russian Academy of Sciences, 9 Piip Boulevard, Petropavlovsk-Kamchatsky 683006, Russia

${ }^{12}$ The Moscow Association for NLC Research, Kosygina Street 17, 119334 Moscow, Russia

*Corresponding author: audrius.dubietis@ ff.vu.It

Received 11 May 2011; revised 29 July 2011; accepted 5 August 2011; posted 10 August 2011 (Doc. ID 147264); published 21 September 2011

\begin{abstract}
Noctilucent, or "night-shining," clouds (NLCs) are a spectacular optical nighttime phenomenon that is very often neglected in the context of atmospheric optics. This paper gives a brief overview of current understanding of NLCs by providing a simple physical picture of their formation, relevant observational characteristics, and scientific challenges of NLC research. Modern ground-based photographic NLC observations, carried out in the framework of automated digital camera networks around the globe, are outlined. In particular, the obtained results refer to studies of single quasi-stationary waves in the NLC field. These waves exhibit specific propagation properties-high localization, robustness, and long lifetime - that are the essential requisites of solitary waves. (c) 2011 Optical Society of America OCIS codes: $\quad 010.1290,010.1615,010.2940$
\end{abstract}

0003-6935/11/280F72-08 $\$ 15.00 / 0$

(C) 2011 Optical Society of America 


\section{Introduction}

Noctilucent clouds (NLCs) are a beautiful optical phenomenon that could be observed during short summer nights. NLC visibility period extends from the end of May until the middle of August, with peak occurrence probability in one or two weeks after the summer solstice. NLCs are the highest clouds in the terrestrial atmosphere; they form at an altitude range of $80-85 \mathrm{~km}$ [1], far above ordinary clouds, whose development is limited to tropospheric altitudes that usually do not exceed $15 \mathrm{~km}$. For a ground-based observer, NLCs appear as transparent silver-blue patterns that are illuminated by the Sun below the horizon and that are easily discernible against the darker background sky; see Fig. 1. Visual NLC appearance is somewhat similar to tropospheric cirrus clouds; in particular, fine cloud structures resemble those seen in cirrostratus and cirrocumulus. In fact, NLCs are so tenuous that they can be distinguished only $1 \mathrm{~h}$ or so after sunset or before sunrise, when the background sky becomes dark enough: the lower atmosphere already lies in the shadow, while the upper atmosphere is still exposed to sunlight. Exceptional NLC displays may occupy the entire twilight arch; in the hour of early nautical twilight, the NLC field might extend up to zenith or even into the southern part of the sky.

From the ground, NLCs are observed from midand high-latitude $\left(50^{\circ}-65^{\circ}\right)$ locations, where the most favorable geometrical viewing conditions, i.e., illumination of the twilight arch and the duration of twilight, occur [1]. Although NLCs are usually considered high-latitude phenomenon, there exists evidence that, on rare occasions, these clouds could be observed from unusually low latitudes. In this regard, NLC observations were reported from Logan, Utah $\left(41.7^{\circ} \mathrm{N}\right)$ in 1999 [2], and more recently from Palmela, Portugal $\left(38 . \overline{6}^{\circ} \mathrm{N}\right)$ in 2007 and from Taslyayla Plateau, Turkey $\left(40.5^{\circ} \mathrm{N}\right)$ in 2008 [3].

NLCs are composed of tiny ice crystals that occur in the upper polar mesosphere, at the vicinity of the mesopause, which, during summer months, exhibits very cold temperatures that permit ice crystal

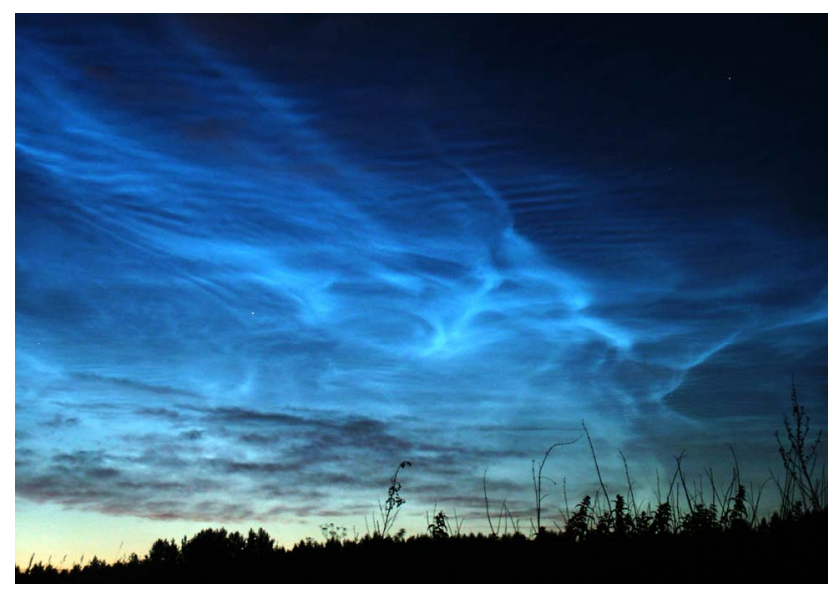

Fig. 1. (Color online) Noctilucent clouds, as seen from Salakas, Lithuania $\left(55.6^{\circ} \mathrm{N}, 26.2^{\circ} \mathrm{E}\right)$. formation. Typical dimensions of ice crystals vary in the range from 20 to $150 \mathrm{~nm}$, with an average value being close to $50 \mathrm{~nm}$ [4]. These tiny ice crystals serve as efficient Mie scatterers located almost outside an apparent atmosphere. The scattered light, as it propagates through the atmosphere, obliquely passes the ozone layer, where it experiences redshifted absorption (due to the Chappuis band); this yields a characteristic silver-blue color that is perceived by a ground-based observer.

NLCs were discovered in the summer of 1885 , when a sudden and unexpected outburst of remarkable night-shining clouds during the twilight hours was reported across Europe; see [1] for a comprehensive historical account. In this regard, NLCs constitute the newest naked-eye optical phenomenon, which has been studied by visual and photographic methods on a more or less regular basis since $[5,6]$. The discovery of an extended mesospheric cloud layer above the entire polar regions in 1972 [7], which was termed polar mesospheric clouds (PMCs), has set a new landmark in NLC investigations. In fact, PMCs form over polar regions that in summertime are almost continuously exposed to sunlight; therefore, PMCs could be detected only by instrumental techniques. In this view, NLCs and PMCs constitute the same phenomenon that is observed by different means; NLCs, as observed from the ground, are considered as a visible edge of a large PMC layer.

In this paper, we provide a brief overview on current understanding of NLCs and their modern groundbased observations by a world-wide automated digital camera network. A particular emphasis is given to studies of single, localized, and quasi-stationary waves that occur in the NLC field. This type of wave produces strong atmospheric disturbances and constitutes an interesting, almost uninvestigated, wave phenomenon in the mesosphere.

\section{Noctilucent Cloud Formation}

NLC formation takes place in the region where a combination of chemical, thermal, and dynamical processes gives rise to very specific environmental conditions [8]. The polar and near-polar mesopause, which defines the boundary between the mesosphere and the thermosphere, exhibits striking differences of seasonal thermal structure: winter polar mesopause is comparatively warm, whereas summer polar mesopause becomes the coldest place on Earth (see Fig. 2 for an example); here, temperature drops to as low as $\sim 130 \mathrm{~K}$ during the early summer (within a few weeks around the summer solstice). This is because the temperature of the summer polar mesopause (which is continuously illuminated by direct sunlight) significantly departs from the radiative equilibrium as a result of adiabatic cooling imposed by dynamical processes originating from vertical air motion conjugated with a complex wave activity in the middle atmosphere [9]. The key role in these processes is supposed to belong to break-up of upward 


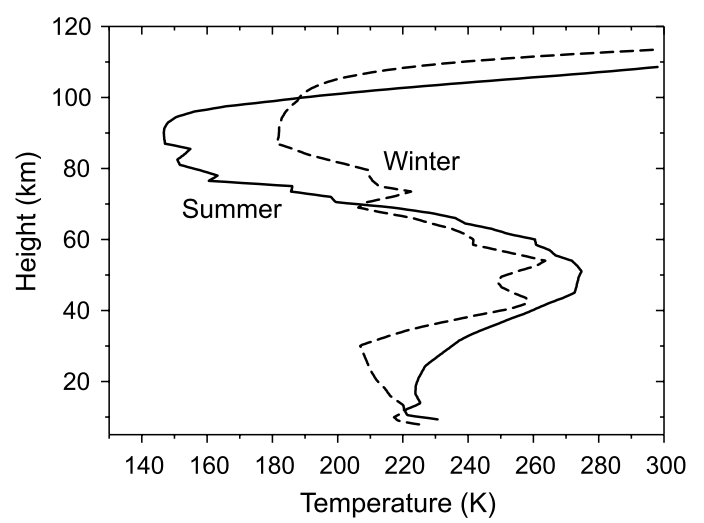

Fig. 2. Comparison of vertical temperature profiles in winter (dashed curve) and in summer (solid curve) at $\sim 60^{\circ} \mathrm{N}$, as measured by the Halogen Occultation Experiment (HALOE) on 14 February 2004 and 13 July 2004, respectively.

propagating internal gravity waves (oscillations of large air parcels under buoyancy and gravity forces) that are excited by large tropospheric weather disturbances during the summer months.

It is generally accepted that three key factors play an essential role in NLC formation: low temperature, sufficient concentration of water vapor, and the presence of condensation nuclei [10]. Indeed, formation of NLCs has been related to extremely low temperature around the summer mesopause [11], and recent results that combine ground-based photographic NLC observations by a digital camera network and satellite data confirm this relationship in great detail [12]. It is now clear that NLCs form when the temperature falls below the frost point temperature of water vapor. Note that the upper mesosphere is very dry; the average water vapor mixing ratio at the mesopause height is only $\sim 5$ parts in $10^{6}$ by volume, which yields a frost-point temperature of $\sim 146 \mathrm{~K}$. Although sources and sinks of water vapor in the mesosphere are still under investigation, it is thought that oxidation of methane gas in the mesosphere serves as a major contributor to in situ production of water vapor. According to this view, increased methane emissions facilitated the NLC formation process and boosted the occurrence of visible NLCs in the late 19th century [13]. Interestingly, the water ice composition of NLCs was proved just quite recently from satellite-based infrared spectral measurements [14]. However, real NLC crystals have never been precisely sampled to date and, as yet, their shape is not known.

Figure 3 illustrates a simplified one-dimensional schematic picture of NLC formation. Under extreme temperature conditions that occur at the vicinity of the summer mesopause, the water vapor condensation process starts at an $\sim 90 \mathrm{~km}$ height, with ions and particles from meteoric debris serving as condensation nuclei. The nanometer-sized ice particles produce no visual effect; however, in interacting with a very specific environment, they become electrified. The inhomogeneities of the charged particle distribution produce strong backscattering of very

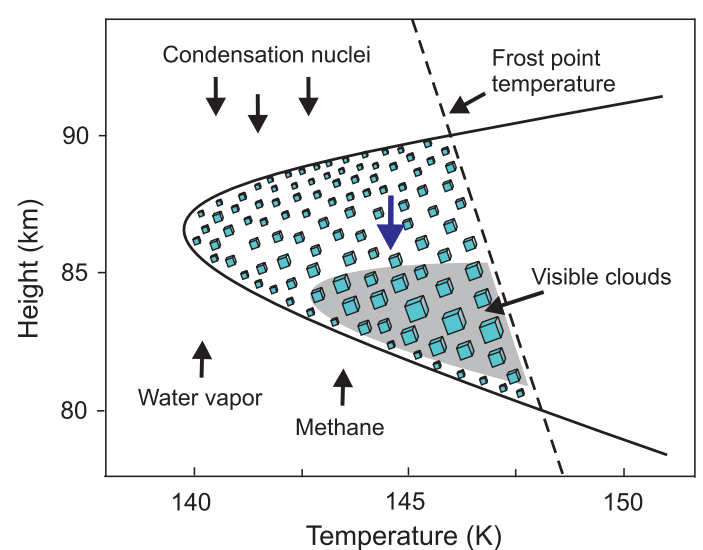

Fig. 3. (Color online) Schematic diagram of NLC formation and contributing processes.

high-frequency radio waves; the effect is known as polar mesospheric summer echoes (PMSEs) [15]. As the ice crystals grow in size, they descend upon Earth's gravity force. A narrow layer between 85 and $80 \mathrm{~km}$ is populated by ice crystals with dimensions $>30 \mathrm{~nm}$ that are able to produce efficient light scattering, which is seen as NLCs. Below $80 \mathrm{~km}$, ambient temperature exceeds the frost point, and ice crystals rapidly evaporate. The growth and evaporation rates are very different. The average growth rate of the ice crystals is rather slow; it takes approximately $9 \mathrm{~h}$ for the crystals to reach the size of $100 \mathrm{~nm}$ [1], while the evaporation rate is much more rapid; a whole NLC field might fade and disappear in a few tens of minutes. Of course, the above picture is only qualitative; in reality, NLC formation is very much affected by dynamical processes in threedimensional space, such as atmospheric tides and planetary and gravity waves, which control the NLC formation process and serve as sources of NLC variability on different length and time scales.

On the other hand, the environmental conditions around the mesopause are subject to extraterrestrial forcing, i.e., variable solar activity, which drives the space weather. Indeed, a direct relationship between the NLC occurrence frequency and solar activity is now reliably established. Ample long-term groundbased [16-20] and satellite observations [21,22] revealed that NLC characteristics vary inversely with the solar activity: in general, NLC occurrence frequency and brightness increase in the years of solar minimum, and vice versa. In this regard, another important issue concerns the long-term trends in variability of NLCs. Since methane emissions are continuously increasing due to agricultural and industrial activities, and methane is directly involved in NLC formation because it produces significant water vapor amounts in the mesosphere, NLCs are supposed of serving as tracers of global climate change in the middle and upper atmosphere [23], although this subject still remains controversial [24]. To this end, positive trends on PMC occurrence frequency and albedo are detected from satellite observations $[21,22]$. However, trends in NLC occurrence 
frequency and brightness derived from visual and photographic ground-based observations still lack statistical significance [17-20]. This issue sets an important scientific topic for future investigations, which require high-quality and uniform long-term data sets.

\section{World-Wide Digital Camera Network}

Otto Jesse in Germany was perhaps the first to start photographic NLC observations on a regular basis in 1887 [25]; even now, NLC photography is still in use and serves as an indispensable and inexpensive tool for NLC studies. Photographic observations became especially efficient with the development of low-cost high-quality digital cameras that can be operated in automatic shooting mode. Digital images can now be precisely calibrated and analyzed, thus providing valuable information on dynamical processes that leave their footprints in the NLC layer.

The international photographic network for continuous NLC monitoring started in 2004 in Moscow, Novosibirsk (both Russia), and Lund (Sweden). The network geography has extended for successive years [26], and at present it includes seven observing sites situated around the globe (see Fig. 4): Port Glasgow, Scotland $\left(55^{\circ} 56^{\prime} \mathrm{N}, 04^{\circ} 41^{\prime} \mathrm{W}\right)$; Athäbasca, Canada $\left(54^{\circ} 44^{\prime} \mathrm{N}, 113^{\circ} 19^{\prime} \mathrm{W}\right)$; Kamchatka, Russia $\left(53^{\circ} 04^{\prime} \mathrm{N}\right.$, $\left.158^{\circ} 37^{\prime} \mathrm{E}\right)$; Novosibirsk, Russia $\left(54^{\circ} 52^{\prime} \mathrm{N}, 83^{\circ} 06^{\prime} \mathrm{E}\right)$; Moscow, Russia $\left(56^{\circ} 00^{\prime} \mathrm{N}, 37^{\circ} 29^{\prime} \mathrm{E}\right)$; Vilnius, Salakas, and Vidiškes, Lithuania (average coordinates $\left.55^{\circ} 00^{\prime} \mathrm{N}, 26^{\circ} 00^{\prime} \mathrm{E}\right)$; and Aarhus and Silkeborg, Denmark (average coordinates $56^{\circ} 10^{\prime} \mathrm{N}, 09^{\circ} 50^{\prime} \mathrm{E}$ ). There are two supplementary digital cameras located in the Moscow region (Zvenigorod and Krasnogorsk),

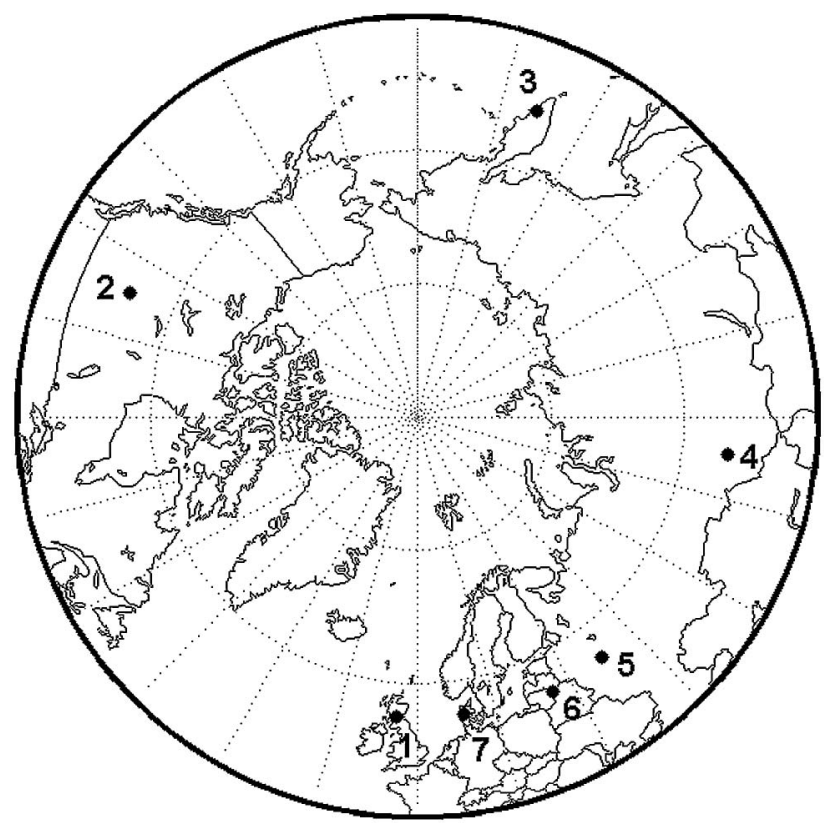

Fig. 4. Map of the ground-based photographic network locations for NLC monitoring: 1, Port Glasgow (UK); 2, Athabasca (Canada); 3, Kamchatka; 4, Novosibirsk; 5, Moscow (all Russia); 6, Salakas, Vilnius, and Vidiškes (average location, Lithuania); 7, Aarhus and Silkeborg (Denmark). separated from the first one by 50 and $20 \mathrm{~km}$, respectively. At present, the NLC cameras in Canada and Denmark are connected to the Internet (during the summer time), providing real-time data, images from Novosibirsk are downloaded via the Internet in a semiautomated manner, and images from other cameras are processed after the end of the observing season.

The NLC cameras are located along the $54^{\circ}-56^{\circ} \mathrm{N}$ latitude circle, where almost ideal conditions for NLC observations occur. Moreover, such geographical locations provide comparable NLC observations due to equal twilight illumination conditions, as well as very similar physical conditions in the mesopause, since temperature and vertical and horizontal winds are latitude dependent. Wide geographical coverage allows study of NLC activity on local and continental scales, as well as effects due to gravity and planetary waves. Each camera operates with a similar program from the end of May until the middle of August and takes images of the twilight segment between 22:00 and 05:00 local time (LT) in the automatic shooting mode. Here and in the following sections, "local time" refers to Daylight Saving Time (Time Zone LT $+1 \mathrm{~h}$ ). The time interval between successive frames varies from 1 to $3 \mathrm{~min}$, depending on the illumination conditions of the twilight sky. The field of view of the cameras ranges from $55^{\circ} \times 42^{\circ}$ to $78^{\circ} \times 59^{\circ}$, depending on the particular camera model and lenses used.

Recently we developed a new software for the NLC image processing. This allows for very precise calibration of an image using celestial coordinates of the reference stars corrected for atmospheric refraction. This is achieved by applying the standard pinhole camera lens model (i.e., the mathematical relationship between the coordinates of an observed object and its projection onto the image plane) and corrected for lens distortion effects by accounting for additional terms in the form of the power series of the fourth order. Also, the NLC image software corrects for the nutation of the Earth's axis, which is an important source of error in position of the stars when processing an image of small field of view $\left(10^{\circ} \times 10^{\circ}\right)$, e.g., fine details in the NLC field. As a result, the accuracy of the calibrated NLC image is limited to just a pixel size across the whole image area, which corresponds to uncertainty in altitude of $100-600 \mathrm{~m}$ at a $83 \mathrm{~km}$ height, depending on the elevation angle of an observed NLC detail; this is compared to the uncertainty of the NLC height estimation obtained by the lidar and radar technique for studies of the NLC and PMSE layers, respectively.

\section{Waves in Noctilucent Clouds}

Noctilucent clouds serve as a perfect natural laboratory for the investigation of wave activity around the summer mesopause. Multipoint observations of NLCs around the globe allow for investigations of effects imposed by huge atmospheric planetary waves having wavelengths from several thousand up to $20,000 \mathrm{~km}$ in the subpolar and polar regions and 
typical periods of 2,5 , and 16 days. Planetary waves are traveling global-scale atmospheric oscillations that produce strong disturbances of the basic state of the atmosphere, inducing temperature variations of $\pm 1-8 \mathrm{~K}$ at the mesopause height $[27,28]$. The effects of planetary waves on PMSE and NLC occurrences was revealed by a number of observations; see, e.g., [29]. In this regard, analysis of the network data confirmed a clear influence of the 2- and 5-day planetary waves on the geographical distribution of the occurrence frequency and brightness variations of NLCs [26]. More recently, the observed variations of NLC parameters were compared to temperature variations at the mesopause height, as measured by NASA's Aura satellite. It was shown that the 2- and 5-day planetary wave activity and NLC brightness are in anticorrelation: NLC brightness is amplified at the cold phase of the wave and vice versa, and this behavior is reliably established from each network site [12]. The impact of 16-day planetary wave activity seems more complicated and should be further studied; it is possible that this kind of wave is responsible, to some extent, for variations of the overall seasonal NLC climatology, e.g., time of seasonal temperature minima and related variations of NLC characteristics.

While the planetary waves modulate NLC brightness and occurrence frequency on the scale of days, the effect of atmospheric gravity waves is immediately noticed in the NLC field. In this regard, NLC observations readily provide important information on the characteristics of atmospheric gravity waves of small (wavelength of $5-10 \mathrm{~km}$ ), medium $(10-100 \mathrm{~km})$, and large scales $(100-1000 \mathrm{~km})$, which produce large temperature variations of up to $\pm 5-$ $10 \mathrm{~K}$ on a much smaller time and length scale than the planetary waves do [30]. Indeed, a distinctive feature of NLCs is their wavelike structure (see Fig. 1). Based on this wavelike appearance, the morphological NLC forms are generally classified into four major types [31]: type I ("veil") is an amorphous and featureless NLC field, type II ("bands") are extended streaks with sharp or diffuse edges, type III ("billows") are patterns of closely spaced short waves or ripples, and type IV ("whirls") are partial rings whose angular dimensions may vary up to tens of degrees. The NLC displays very often exhibit a mix of various NLC forms that change in both space and time, producing rather complex wave fields.

The wave structures in the NLC field are characterized by different dimensions and lifetimes as they originate from different dynamical processes that take place at the mesopause height. The small-scale, billow-type wave structures are highly dynamic, short-lived (typically, their lifetime is of the order of 5-10 min), and short-wavelength (a few kilometers) formations that originate from instabilities associated with local wind shear or wave breaking [32]. Strong turbulence at the mesopause level gives rise to even more complex small-scale structures, such as vortices of $1-1.5 \mathrm{~km}$ in diameter, that considerably influence the NLC dynamics [33]. In contrast, waves of much larger scales, referred to as "bands," appear as sequences of distinct parallel streaks that extend from tens to hundreds of kilometers and persist up to several hours. These waves are the signatures of upward propagating short-period internal gravity waves with vertical wavelengths up to a few tens of kilometers originating from tropospheric sources, which produce horizontally propagating disturbances at the mesopause level [34]. The wavelength of these waves (a distance between adjacent wave crests) varies in rather broad confines (from tens to hundreds of kilometers). However, short wavelengths of $20-45 \mathrm{~km}$ are most frequently observed, as outlined recently by satellite imagery and ground-based observations [35,36]. An interesting feature associated with the motion of these wave formations is that they preferentially move toward the north-north-east [36], as opposed to the direction of motion of the ambient NLC field, which typically moves towards the south-west as a result of prevailing winds in the summer mesosphere.

\section{Single Localized Waves in the Noctilucent Cloud Field}

On rare occasions, extended (up to several hundreds of kilometers) bands in the NLC field occur as single, quasi-stationary waves that are remarkably localized in the direction of propagation. These waves were first brought to attention almost half a century ago [37]; however, because of the scarcity of observations, the complete characterization of these interesting waves is still missing. Only recently, more detailed lidar observations of a single, elongated wave that had length of $250 \mathrm{~km}$, was localized only within $10 \mathrm{~km}$ along the propagation direction, and was visible over a period of 30 min were reported [38].

As a first step toward quantitative characterization of the single localized waves that occur in the NLC field, we present a case study of a spectacular quasi-stationary wave that was observed from Lithuania on the night of 28/29 June 2010. The event was simultaneously recorded by two cameras located at Vidiškes $\left(55^{\circ} 22^{\prime} \mathrm{N}, 26^{\circ} 12^{\prime} \mathrm{E}\right)$ and Vilnius $\left(54^{\circ} 41^{\prime} \mathrm{N}\right.$, $25^{\circ} 18^{\prime} \mathrm{E}$ ), which operated in a synchronous shooting regime, taking images every minute. The localized wave occurred at 01:28 LT as an almost horizontally oriented narrow bright stripe that was projected onto the top edge of the NLC field. Figure 5 shows four images (separated by 20 min time intervals) of the quasi-stationary wave as recorded from Vidiškes. While the whole NLC field moved in the direction of the south-south-east (as estimated from the motion of fine structures present in the NLC field), the single wave was moving toward the north-northwest (azimuth of propagation direction $348^{\circ}$ ) at an average speed of just $5.0 \pm 1.7 \mathrm{~m} / \mathrm{s}$ with respect to a ground-based observer, which created the illusion of an almost standing wave.

Observations from the two points allowed height estimations of the relevant NLC details with 

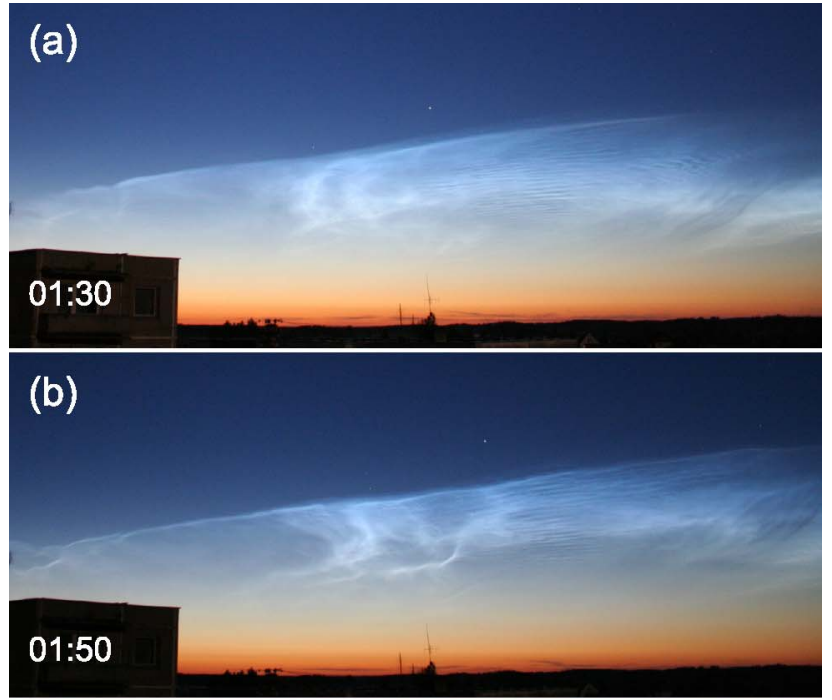

\section{(c)}

\section{2:10}

\section{(d)}

\section{$02: 30$}

Fig. 5. (Color online) Dynamics of a quasi-stationary single wave in the NLC field. The size of each image is $45^{\circ} \times 20^{\circ}$. Numbers at the bottom of the images indicate the local time.

reasonable accuracy $(580 \mathrm{~m})$, despite the low elevation of the NLC field. The height range of the ambient NLC layer (which is projected below the wave) was found to be between 82.7 and $83.7 \mathrm{~km}$, which is consistent with the average NLC height of $82.9 \mathrm{~km}$ [1]. Simultaneous height estimations across the localized wave revealed a rather complex and, at the same time, surprising picture: the average height of its left edge was found to be between 83.4 and $83.9 \mathrm{~km}$, while the average height of its right edge was found to be between 80.7 and $81.9 \mathrm{~km}$. This finding suggests that there are actually two localized waves at different heights and that are projected onto the line of sight as a single stripe. The existence of two distinct localized waves becomes more clear in Figs. 5(c) and 5(d): note how apparent separation between the two localized waves increases, as a huge perturbation (seen as brighter and darker, nearly vertically oriented features at the center of images, supposedly induced by a strong gravity wave) passes from left to right. Therefore, it is readily possible that two waves are located at different heights due to positioning at different phases (amplitudes) of the propagating gravity-wave-induced perturbation. Unfortunately, unfavorable viewing geometry did not allow estimating the amplitudes of localized waves. Nevertheless, a striking feature shared by both waves is that they remained remarkably localized in the direction of propagation (the wave width varied just from 4.7 to $6.6 \mathrm{~km}$ ) and for almost $1.5 \mathrm{~h}$ $(86 \pm 2 \mathrm{~min})$ until they faded at 02:54 LT, and high localization was maintained across the full length of the waves $(\sim 200 \mathrm{~km}$ for the wave on the left and $\sim 85 \mathrm{~km}$ for the wave on the right, respectively).

It is important to mention that the considered wave is a rare type of localized wave, serving as a border of an NLC field. The unusual, sharp-bordered appearance of the entire NLC field, to some extent resembles the so-called "mesospheric wall," the phenomenon that is occasionally observed in the air-glow emission patterns [39]. Mesospheric walls, or wall waves, are produced by large-amplitude gravity waves that induce dramatic temperature change (up to $60 \mathrm{~K}$ ) and steep temperature gradients that separate two large atmospheric volumes with completely different environmental conditions [40]. To this end, the present case is perhaps the first observation of the "mesospheric wall" in NLCs.

To quantify the essential properties of the single localized waves, in what follows we present the first statistical results obtained by NLC observations from Lithuania in 2008-2010. During this period, a total of 86 NLC displays were captured by timelapse photography, which revealed 18 single and localized wave events. For each event, the individual properties - width, length, lifetime, velocity, and propagation direction of the single waves-were measured. The basic characteristics of 18 single wave events emphasizing their exceptional features are summarized in Fig. 6. Figure 6(a) shows that the width of individual waves ranges from 1.2 to $8.3 \mathrm{~km}$, and the width of $50 \%$ of the single wave events is confined within a narrow interval between 4 and $6 \mathrm{~km}$, suggesting that these single waves are indeed highly localized in the direction of propagation. The length (wave extension in the direction perpendicular to propagation) of the single waves was found to be from 50 to $450 \mathrm{~km}$. Another distinctive feature of single localized waves is their long lifetime, which varies from 25 to $55 \mathrm{~min}$ (60\% of events), as seen from Fig. 6(b), which clearly distinguishes them from narrow but short-lived ripple-type waves. In the exceptional cases, visibility of the localized waves may exceed $1 \mathrm{~h}$, as attested by the case study presented above. Figure 6(c) illustrates the distribution of the propagation direction, where $0^{\circ}$ azimuth refers to the north. Large asymmetry in the propagation direction indicates that these waves preferentially move in the directions ranging from north-north-west to northnorth-east, as opposed to south-west motion of the ambient NLC field. 

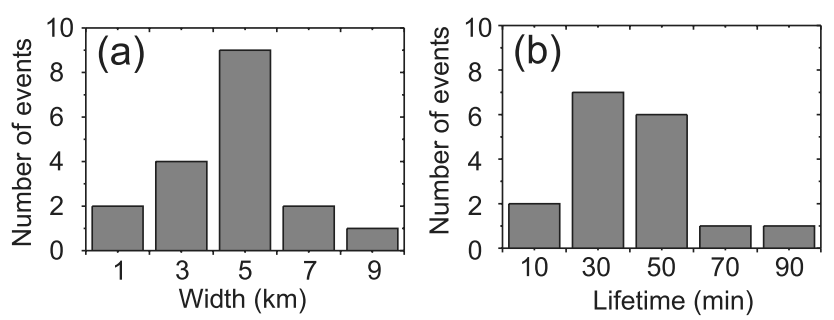

(c)

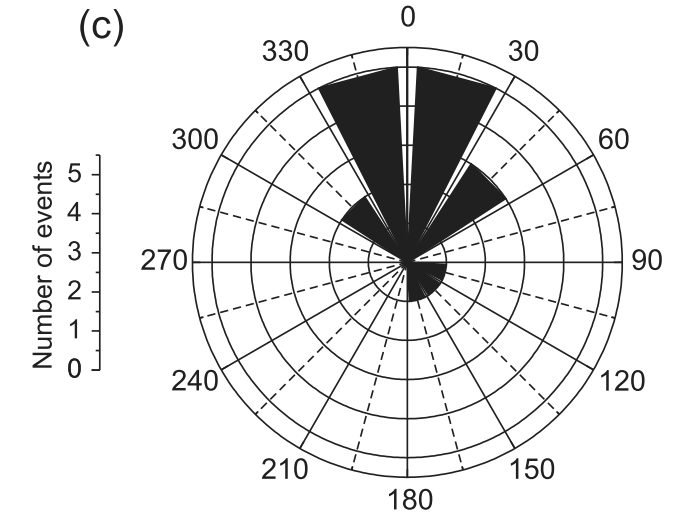

Fig. 6. Statistical distributions of the single wave properties: (a) wave width, (b) lifetime, and (c) propagation direction.

The exceptional features of the single waves clearly distinguish them from other types of waves observed in the NLC field. Specifically, high localization in the propagation direction, long lifetime, and robustness of the single waves fulfil the criteria of solitary waves, i.e., localized waves that are robust against perturbations and propagate over large distances without apparent distortions of their initial shape. High localization and robustness of solitary waves is governed by a balance between dispersion spreading and nonlinearity; the presence of the nonlinearity at the height scale of the NLC layer was indeed considered [41]. A detailed statistical analysis of the data obtained from other network sites is in progress toward building a comprehensive database of the single localized wave events, with detailed examination of the wave characteristics from twostation observations that are currently available from pairs of nearby NLC cameras located in Moscow, Denmark, and Lithuania.

\section{Conclusions}

One-hundred and twenty-five years since their discovery, NLCs still comprise a fascinating topic in atmospheric research. In line with a variety of methods (radar, lidar, rocket sounding, and airborne and satellite imagery) currently applied for NLC research, modern photographic NLC observations provide high scientific value in understanding the nature of NLCs and the processes in the mesosphere in general, which for a long time remained the most poorly investigated atmospheric layer due to its direct inaccessibility.

Coordinated observations by a digital groundbased automatic camera network, located in the Northern hemisphere within a narrow $54^{\circ}-56^{\circ}$ latitude circle, enable continuous monitoring of NLCs and their dynamics around the globe on very different, local and continental, scales. Among the results obtained by successful operation of the network during the past years, in this paper, we present what we believe to be the first detailed observations of single localized waves that occur in the NLC field. Even though these results are obtained using just a small amount of the available data, they suggest that the single waves, owing to their exceptional propagation properties (high localization in the propagation direction, which is maintained over a considerable time period, and distinct directionality) are well distinguished from other, much better studied wave formations in NLCs. Certainly, investigations of single localized waves open an interesting research line; a better understanding of the nature of these waves and their possible connections with solitary waves requires more detailed analysis of the observational data (which is now in progress, including estimations of the wave amplitude), supported by theoretical model and numerical simulations.

In general, studies of waves in NLCs are of primary importance for quantifying the wave activity in the atmosphere, identifying the sources and parameters of atmospheric gravity waves and their interactions and propagation effects, that would finally enable us to gain a better understanding of the layered terrestrial atmosphere as a single entity [42].

\section{References}

1. M. Gadsden and W. Schröder, Noctilucent Clouds (Springer, 1989).

2. M. J. Taylor, M. Gadsden, R. P. Lowe, M. S. Zalcik, and J. Brausch, "Mesospheric cloud observations at unusually low latitudes," J. Atmos. Sol. Terr. Phys. 64, 991-999 (2002).

3. Noctilucent cloud observers' homepage, http://www.kersland .plus.com.

4. A. A. Kokhanovsky, "Microphysical and optical properties of noctilucent clouds," Earth-Sci. Rev. 71, 127-146 (2005).

5. B. Fogle and B. Haurwitz, "Noctilucent clouds," Space Sci. Rev. 6, 279-340 (1966).

6. M. Gadsden, "Noctilucent clouds," Space Sci. Rev. 33, 279-334 (1982).

7. T. M. Donahue, B. Guenther, and J. E. Blamont, "Noctilucent clouds in daytime: circumpolar particulate layers near the summer mesopause," J. Atmos. Sci. 29, 1205-1209 (1972).

8. G. E. Thomas, "Mesospheric clouds and the physics of the mesopause region," Rev. Geophys. 29, 553-575 (1991).

9. D. C. Fritts and M. J. Alexander, "Gravity wave dynamics and effects in the middle atmosphere," Rev. Geophys. 41, 1003 (2003).

10. M. Rapp and G. E. Thomas, "Modelling the microphysics of mesospheric ice particles: assessment of current capabilities and basic sensitivities," J. Atmos. Sol. Terr. Phys. 68, 715-744 (2006).

11. J. S. Theon, W. Nordberg, and W. S. Smith, "Temperature measurements in noctilucent clouds," Science 157, 419-421 (1967).

12. P. Dalin, N. Pertsev, A. Dubietis, M. Zalcik, A. Zadorozhny, M. Connors, I. Schofield, T. McEwan, I. McEachran, S. Frandsen, O. Hansen, H. Andersen, V. Sukhodoev, V. Perminov, R. Balčiunas, and V. Romejko, "A comparison between goundbased observations of noctilucent clouds and Aura satellite 
data," J. Atmos. Solar Terr. Phys., doi:10.1016/j.jastp.2011. 01.020 (to be published).

13. G. E. Thomas, J. J. Olivero, E. J. Jensen, W. Schroeder, and O. B. Toon, "Relation between increasing methane and the presence of ice clouds at the mesopause," Nature 338, 490-492 (1989).

14. M. Hervig, R. E. Thompson, L. L. Gordley, J. M. Russell, and M. E. Summers, "First confirmation that water ice is the primary component of polar mesospheric clouds," Geophys. Res. Lett. 28, 971-974 (2001).

15. T. Hartquist, O. Havnes, and M. Kassa, "Exploring polar mesospheric summer echoes," Astron. Geophys. 50, 1.8-1.14 (2009).

16. M. Gadsden, "The North-West Europe data on noctilucent clouds: a survey," J. Atmos. Solar Terr. Phys. 60, 1163-1174 (1998).

17. V. A. Romejko, P. A. Dalin, and N. N. Pertsev, "40 years of noctilucent cloud observations near Moscow: database and simple statistics," J. Geophys. Res. 108, 8443 (2003).

18. P. Dalin, S. Kirkwood, H. Andersen, O. Hansen, N. Pertsev, and V. Romejko, "Comparison of long-term Moscow and Danish NLC observations: statistical results," Ann. Geophys. 24, 2841-2849 (2006).

19. S. Kirkwood, P. Dalin, and A. Rèchou, "Noctilucent clouds observed from the UK and Denmark-trends and variations over 43 years," Ann. Geophys. 26, 1243-1254 (2008).

20. A. Dubietis, P. Dalin, R. Balčiūnas, and K. Černis, "Observations of noctilucent clouds from Lithuania," J. Atmos. Solar Terr. Phys. 72, 1090-1099 (2010).

21. M. T. DeLand, E. P. Shettle, G. E. Thomas, and J. J. Olivero, "A quarter century of satellite polar mesospheric cloud observations," J. Atmos. Solar Terr. Phys. 68, 9-29 (2006).

22. E. P. Shettle, M. T. DeLand, G. E. Thomas, and J. J. Olivero, "Long term variations in the frequency of polar mesospheric clouds in the Northern Hemisphere from SBUV," Geophys. Res. Lett. 36, L02803 (2009).

23. G. E. Thomas, "Are noctilucent clouds harbingers of global change in the middle atmosphere?" Adv. Space Res. 32, 1737-1746 (2003).

24. U. von Zahn, “Are noctilucent clouds truly a 'miner's canary' of global change?" EOS Trans. Am. Geophys. Union 84, 261-268 (2003).

25. W. Schröder, "Otto Jesse and the investigation of noctilucent clouds 115 years ago,” Bull. Am. Meteorol. Soc. 82, 24572468 (2001).

26. P. Dalin, N. Pertsev, A. Zadorozhny, M. Connors, I. Schofield, I. Shelton, M. Zalcik, T. McEwan, I. McEachran, S. Frandsen, O. Hansen, H. Andersen, V. Sukhodoev, V. Perminov, and V. Romejko, "Ground-based observations of noctilucent clouds with a northern hemisphere network of automated digital cameras,” J. Atmos. Solar Terr. Phys. 70, 1460-1472 (2008).

27. P. J. Espy and G. Witt, "Observation of a quasi 16-day oscillation in the polar summer mesospheric temperature," Geophys. Res. Lett. 23, 1071-1074 (1996).
28. A. Pogoreltsev, "Simulation of planetary waves and their influence on the zonally averaged circulation in the middle atmosphere," Earth Planets Space 51, 773-784 (1999).

29. S. Kirkwood, V. Barabash, B. U. E. Brändström, A. Moström, K. Stebel, N. Mitchell, and W. K. Hocking, "Noctilucent clouds, PMSE and 5-day planetary waves: a case study," Geophys. Res. Lett. 29, 1411-1414 (2002).

30. M. Rapp, F.-J. Lübken, and A. Müllemann, "Small scale temperature variations in the 12 vicinity of NLC: experimental and model results," J. Geophys. Res. 107, 4392-4412 (2002).

31. M. Gadsden and P. Parviainen, Observing Noctilucent Clouds (The International Association of Geomagnetism and Aeronomy, 2006).

32. D. C. Fritts, J. R. Isler, G. E. Thomas, and Ø. Andreassen, "Wave breaking signatures in noctilucent clouds," Geophys. Res. Lett. 20, 2039-2042 (1993).

33. P. Dalin, N. Pertsev, S. Frandsen, O. Hansen, H. Andersen, A. Dubietis, and R. Balciunas, "A case study of the evolution of a Kelvin-Helmholtz wave and turbulence in noctilucent clouds," J. Atmos. Solar Terr. Phys. 72, 1129-1138 (2010).

34. C. O. Hines, "A possible source of waves in noctilucent clouds," J. Atmos. Sci. 25, 937-942 (1968).

35. A. Chandran, D. W. Rusch, A. W. Merkel, S. E. Palo, G. E. Thomas, M. J. Taylor, S. M. Bailey, and J. M. Russell III, "Polar mesospheric cloud structures observed from the CIPS experiment on the AIM spacecraft: atmospheric gravity waves as drivers for longitudinal variability in PMC occurrence," J. Geophys. Res. 115, D13102 (2010).

36. P.-D. Pautet, J. Stegman, C. M. Wrasse, K. Nielsen, H. Takahashi, M. J. Taylor, K. W. Hoppel, and S. D. Eckermann, "Analysis of gravity waves structures visible in noctilucent clouds," J. Atmos. Solar Terr. Phys., doi:10.1016/ j.jastp.2010.06.001 (to be published).

37. G. Witt, "Height, structure and displacements of noctilucent clouds," Tellus 14, 1-18 (1962).

38. G. Baumgarten, J. Fiedler, K. H. Fricke, M. Gerding, M. Hervig, P. Hoffmann, N. Müller, P.-D. Pautet, M. Rapp, C. Robert, D. Rusch, C. von Savigny, and W. Singer, "The noctilucent cloud (NLC) display during the ECOMA/MASS sounding rocket flights on 3 August 2007: morphology on local and global scales," Ann. Geophys. 27, 953-965 (2009).

39. G. R. Swenson, J. Qian, J. M. C. Plane, P. J. Espy, M. J. Taylor, D. N. Turnbull, and R. P. Lowe, "Dynamical and chemical aspects of the mesospheric $\mathrm{Na}$ "wall" event on October 9, 1993 during the Airborne Lidar and Observations of Hawaiian Airglow (ALOHA) campaign,” J. Geophys. Res. 103, 63616380 (1998).

40. F. Li, G. R. Swenson, A. Z. Liu, M. Taylor, and Y. C. Zhao, "Investigation of a "wall" wave event," J. Geophys. Res. 112 D04104 (2007).

41. M. Gadsden, "Noctilucent clouds," Q. J. R. Astron. Soc. 27, 351-366 (1986)

42. M. J. Jarvis, "Bridging the atmospheric divide," Science 293, 2218-2219 (2001). 